Review

\title{
Quantifying Remission Probability in Type 2 Diabetes Mellitus
}

\author{
Sanjay Kalra ${ }^{1, *}$, Ganapathi Bantwal ${ }^{2}$, Nitin Kapoor ${ }^{3,4} \mathbb{D}$, Rakesh Sahay ${ }^{5} \mathbb{D}$, Saptarshi Bhattacharya ${ }^{6} \mathbb{D}$, \\ Beatrice Anne ${ }^{7}$, Raju A Gopal ${ }^{8}$, Sunil Kota ${ }^{9}$, Ashok Kumar ${ }^{10}$, Ameya Joshi 11 ${ }^{10}$, Debmalya Sanyal ${ }^{12}$, \\ Mangesh Tiwaskar ${ }^{13}$ (D) and Ashok Kumar Das ${ }^{14}$
}

check for

updates

Citation: Kalra, S.; Bantwal, G.; Kapoor, N.; Sahay, R.; Bhattacharya, S.; Anne, B.; Gopal, R.A.; Kota, S.;

Kumar, A.; Joshi, A.; et al.

Quantifying Remission Probability in Type 2 Diabetes Mellitus. Clin. Pract. 2021, 11, 850-859. https://doi.org/ 10.3390/clinpract11040100

Academic Editor: Maurizio Aricò

Received: 23 August 2021

Accepted: 14 October 2021

Published: 9 November 2021

Publisher's Note: MDPI stays neutral with regard to jurisdictional claims in published maps and institutional affiliations.

Copyright: (C) 2021 by the authors. Licensee MDPI, Basel, Switzerland. This article is an open access article distributed under the terms and conditions of the Creative Commons Attribution (CC BY) license (https:// creativecommons.org/licenses/by/ $4.0 /)$.
1 Department of Endocrinology, Bharti Hospital, Karnal 132001, India

2 Department of Endocrinology, St Johns Medical College \& Hospital, Bengaluru 560034, India; mallyaganapathi@rediffmail.com

3 Department of Endocrinology, Diabetes and Metabolism, Christian Medical College, Vellore 632004, India; nitin.endocrine@gmail.com

4 Non Communicable Disease Unit, The Nossal Institute for Global Health, Melbourne School of Population and Global Health, University of Melbourne, Victoria 3010, Australia

5 Department of Endocrinology, Osmania Medical College and Hospital, Hyderabad 500095, India; sahayrk@gmail.com

6 Department of Endocrinology, Max Healthcare, New Delhi 110092, India; saptarshi515@gmail.com

7 Department of Endocrinology, Nizams Institute of Medical Sciences, Hyderabad 500082, India; maglarne@yahoo.com

8 Department of Endocrinology, Endodiab Clinic, Kozhikode 673016, India; drrajugopal@gmail.com

9 Department of Endocrinology, Diabetes and Endocare Clinic, Berhampur 760004, India; diab.endocare@gmail.com

10 Department of Endocrinology, CEDAR Diabetes Thyroid \& Hormone Clinic Panipat, Panipat 132103, India; ashoka08@gmail.com

11 Department of Endocrinology \& Diabetes, Bhaktivedanta Hospital and Research Institute,

Mumbai 401107, India; ameyaable@gmail.com

12 Department of Endocrinology, KPC Medical College, Kolkata 700032, India; drdebmalyasanyal@gmail.com

13 Department of Diabetology, Shilpa Medical Research Centre, Mumbai 400068, India; tiwaskar@gmail.com

14 Department of Endocrinology \& Medicine, Pondicherry Institute of Medical Sciences,

Puducherry 605014, India; ashokdas82@gmail.com

* Correspondence: brideknl@gmail.com

\begin{abstract}
Type 2 diabetes mellitus (T2DM) is a chronic progressive disorder and is associated with significant morbidity and mortality. The concept of T2DM remission and the reversal of diabetic parameters to normal levels has been gaining momentum over the past years. T2DM remission is increasingly being recognized by various global guidelines. Multiple models have been developed and validated for quantifying the extent of remission achieved. Based on favorable clinical evidence, T2DM remission can be considered as the therapeutic goal in diabetes management and, in select cases, as an alternative to expensive treatment options, which can be burdensome as T2DM progresses. This narrative review discusses the available strategies, such as lifestyle interventions, physical activity, bariatric surgery, medical nutrition therapy, and non-insulin glucose-lowering medications, for achieving T2DM remission. Although the concept of T2DM remission has emerged as a realworld option, effective implementation in routine clinical practice may not be feasible until long-term studies prove the efficacy of different approaches in this regard.
\end{abstract}

Keywords: T2DM remission; reversal; type 2 diabetes mellitus; lifestyle interventions; bariatric surgery

\section{Diabetes: A Major Health Burden}

Diabetes is increasingly being recognized as a major global health epidemic [1]. According to the International Diabetes Federation (IDF), about 463 million adults across the world were living with diabetes in 2019. The global prevalence of diabetes is expected to rise from $9.3 \%$ in 2019 to $10.9 \%$ in 2045 . In 2019, there were an estimated 4.2 million deaths worldwide due to diabetes [2]. The complications associated with diabetes are accountable 
for significant morbidity and mortality. The chronic complications of diabetes include macrovascular complications, such as stroke, cardiovascular disease, and peripheral artery disease, and microvascular complications, such as nephropathy, neuropathy, and retinopathy [1]. Diabetes also imposes a significant economic burden, with an estimated health expenditure of USD 760.3 billion in 2019 [2]. People with diabetes are at a high risk for several cardiometabolic ailments and all-cause mortality [3]. Fortunately, a healthy lifestyle and the maintenance of a healthy body weight can prevent or delay diabetes [3].

\section{Diabetes: Preventable, Curable, or Both?}

In simple terms, prevention is defined as the aversion of development of a pathological state. It includes all measures, including definitive therapy to curtail the progression of the disease, at any stage of its course [4]. Since the 1980s, there has been growing interest in the prevention of diabetes through lifestyle changes [5]. This was re-emphasized in 2004 through the recommendations of the Diabetes and Nutrition Study Group (DNSG) of the European Association for the Study of Diabetes (EASD) [5,6]. In fact, several randomized controlled trials (RCTs) have shown that diabetes, specifically type 2 diabetes mellitus (T2DM), is preventable or that its onset can be significantly delayed by reducing body weight, increasing physical activity, and diet modification or with metformin use [5,7-9]. A systematic review of RCTs concluded that lifestyle modification can prevent T2DM, and the reduced risk is maintained for several years after the active intervention [5]. The Mediterranean dietary pattern or recommendation-based healthy dietary changes can be recommended for the long-term prevention of diabetes [5].

The term cure is defined as the restoration of health without any evidence of the disease process when evaluated using any of the available criteria to diagnose the condition or disease in question [10]. Unfortunately, a "cure" for diabetes is not perceived as being able to materialize in the near future. Therefore, the term "cure" is currently not applicable to T2DM, as it has been well documented that the condition has the potential for recurrence [11]. Therefore, it would be misleading to portray the "cure of diabetes" as a treatment goal for individuals with diabetes [12].

\section{Reversal and Remission of T2DM: Are They Synonymous?}

Although diabetes was considered as a chronic and irreversible condition in the past, there has been a shift in the paradigm of management goals in diabetes care. Given that diabetes is incurable, the best expected outcome is slowing the inevitable progression of diabetes or the amelioration of its symptoms [11]. The possibility of reversing T2DM was first indicated decades ago based on the outcomes noted in bariatric surgery patients. Pories et al. showed that in obese people with T2DM, blood glucose levels were normalized following bariatric surgery. About $90 \%$ of the study population remained free of diabetes after 10 years $[13,14]$.

The reversal of diabetes is defined as the maintenance of glycated hemoglobin (HbA1c) levels under the diabetic threshold of $6.5 \%$ for a prolonged period of time without the use of any medications for glycemic control [11]. The global report on diabetes by the World Health Organization (WHO) has acknowledged diabetes reversal and the fact that it can be achieved through calorie restriction and weight loss [15]. Studies have shown that the reversal of diabetes can be achieved by using bariatric surgery or other approaches, such as carbohydrate restriction or low-calorie diets (LCD) [11].

In the available literature, "diabetes reversal" is used almost synonymously with "diabetes remission" [11]. The reversal of the parameters of diabetes, such as hyperglycemia, is termed as "diabetes remission" [12]. Although both the terms "remission" and "reversal" are commonly used in the field of diabetes care, recent consensus supports the use of "remission" in the context of T2DM [10,12]. 


\section{T2DM Remission: Understanding the Basics}

The remission of T2DM is suggested to be the primary clinical goal in the management of diabetes, and it should be promoted as an ideal therapeutic endpoint [12]. There is ample evidence to substantiate the feasibility of achievement of remission in T2DM. There are several means to accomplish remission in T2DM, all of which require the achievement of a sustainable weight loss [10].

\subsection{Defining T2DM Remission}

To understand the concept of T2DM remission, it is essential to have an appropriate and clear definition [12]. The first definition of T2DM remission was proposed by Buse et al. in 2009, stating that remission is the achievement of a glycemic level below the diabetic range, in the absence of any pharmacologic or surgical therapy [16]. A simpler definition was proposed by Nagi et al. in 2019 as the achievement of glycemia lower than the threshold value currently used for the diagnosis of T2DM, which is sustained for a minimum duration of six months after discontinuation of all glucose-lowering therapies [10]. Recently, a more contemporary definition has been proposed by Kalra et al., wherein T2DM remission has been defined as a healthy clinical state associated with the achievement of $\mathrm{HbA1c}$ below the targeted threshold, which is maintained for a minimum period of six months, with or without the continuous use of metformin and/or lifestyle changes, provided the condition is not due to comorbidities, concomitant therapies, or complications [12]. Recently, the consensus report of an international expert group convened by the American Diabetes Association has referred to remission as the sustained metabolic improvement in T2DM to nearly normal levels. Remission has been defined as the return of $\mathrm{HbA} 1 \mathrm{c}$ levels to $<6.5 \%$, which occurs either spontaneously or after an intervention and which persists for $\geq 3$ months in the absence of usual glucose-lowering therapy. In case $\mathrm{HbA} 1 \mathrm{c}$ is considered an unreliable marker of glycemic control, fasting plasma glucose level $<7.0 \mathrm{mmol} / \mathrm{L}(<126 \mathrm{mg} / \mathrm{dL})$ or estimated $\mathrm{HbA} 1 \mathrm{c}<6.5 \%$ as calculated from continuous glucose monitoring values can be used as an alternative criteria for defining remission [17].

\subsection{Levels of T2DM Remission}

T2DM remission can be broadly categorized as partial or complete. Previously, the achievement of glycemic levels below the threshold value for the diagnosis of diabetes, i.e., prediabetic glycemic level, was considered as partial remission. Complete remission implied the maintenance of normal glycemic parameters for a minimum duration of one year $[12,16]$. The term "prolonged remission" was used to define complete remission that was maintained over a duration of more than five years [16].

Recently, the categorization of diabetes remission has been based on metabolic, clinical biochemical, and pharmacologic parameters [12]:

- Metabolic remission: the reversal of insulin secretory defect or insulin resistance.

- Clinical or partial remission: the achievement of HbA1c below an individual's set target.

- Biochemical or complete remission: the achievement of $\mathrm{HbA} 1 \mathrm{c}$ below the threshold value for the diagnosis of diabetes.

- Pharmacological remission: Absence of the requirement of any drug therapy.

\subsection{Predictors and Quantification of T2DM Remission}

Although certain modalities can help in diabetes remission, all diabetes patients do not achieve desirable outcomes. An evaluation of the predictors of remission is hence critical for optimal outcomes. For example, factors that influence diabetes remission following bariatric surgery include higher baseline BMI, younger age, shorter diabetes duration, and better glycemic control before surgery [18]. However, traditionally, only patients with $\mathrm{BMI} \geq 35 \mathrm{Kg} / \mathrm{m}^{2}$ with uncontrolled diabetes were considered as potential candidates for bariatric surgery [19]. The DiRECT trial identified some predictors of T2DM remission in the intervention arm, amongst which early and greater weight loss and 
being on fewer antidiabetic medications were the strongest predictors. While individuals with lower $\mathrm{HbA} 1 \mathrm{c}$ and men were more successful at attaining remission, individuals with anxiety and/or depression had lower success [20]. Again, in patients on intensive insulin therapy, the key predictor of achieving sustained drug-free remission was early intervention, particularly within the first two years of diagnosis [21].

Initially, different sets of predictive factors, such as younger age, shorter duration of diabetes, higher baseline body mass index (BMI), and better glycemic control, were used to determine the rate of diabetes remission. Later, three different models were introduced for the prediction of diabetes remission, which were more practical for clinical use [18]. The pre-operative diabetes remission (DiaRem) score was developed for predicting remission rate in persons with T2DM who had undergone Roux-en-Y gastric bypass (RYGB) surgery [22]. This scoring system is based on parameters such as $\mathrm{HbA1c}$, insulin usage, age, and medications [23]. The scores range from 0 to 22 and are divided into five groups based on the probability of remission. The probability of partial and complete remission of T2DM based on the DiaRem scores are defined as follows: $87 \%, 66 \%, 32 \%, 16 \%$, and $5 \%$ for scores $0-2,3-7,8-12,13-17$, and 18-22, respectively [18].

The diabetes surgery score or the ABCD score was proposed by Lee et al., wherein A stands for age, B stands for BMI, C stands for C-peptide level, and D stands for duration of diabetes [23,24]. For the duration of diabetes, C-peptide levels, and for BMI, a fourpoint score ranging from 0 to 3, are used. While for age, a one-point score is used [23]. After adding the points for all variables, the final $A B C D$ score ranges from 0 to 10 points, with higher scores predicting a higher probability of remission following gastric bypass surgery [23].

The Individualized Metabolic Surgery (IMS) score was devised to guide the selection of procedure for individuals with T2DM based on long-term glucose control ( $>5$ years) $[18,25]$. The nomogram for score calculation is based on the four predictors of long-term remission, i.e., the number of diabetes medications, duration of diabetes, insulin use, and glycemic control (HbA1c $<7 \%$ ). Scores of $\leq 25,25-95$, and $>95$ indicate mild, moderate, and severe disease, respectively $[18,25]$.

\section{Strategies to Achieve T2DM Remission}

Based on the available evidence, the remission of T2DM can be achieved through lifestyle modifications, physical activity, and bariatric surgery [11,26,27]. The 2014 recommendations of the US Preventive Services Task Force support the need for nutritional counseling and physical activity for adults at risk of cardiovascular diseases (CVDs) [28]. The American Heart Association (AHA) suggests the implementation of behavior change techniques, such as goal setting and self-monitoring for promoting lifestyle change $[3,29]$. The ADA suggests referring high-risk individuals with diabetes to health programs for increasing physical activity and to target weight loss [3,30].

\subsection{Lifestyle Modifications}

The existing evidence indicates that the remission of T2DM can be achieved through sufficiently intensive lifestyle modifications [27]. The lifestyle modifications explored for diabetes remission are a low-carbohydrate diet and low-calorie diet (LCD) and medical nutrition therapy (MNT) [11].

\section{- $\quad$ Low-Calorie Diet}

Studies have substantiated the effectiveness of calorie-restricted diets in the successful achievement of T2DM remission, even in the absence of any pharmacological intervention [31]. Calorie restriction facilitates the normalization of hepatic glucose output; beta-cell function, including secretory capacity; visceral fat; indices of insulin resistance; and insulin sensitivity [31]. Findings from a clinical audit of 12 obese persons with T2DM (baseline median $\mathrm{HbA} 1 \mathrm{c} 9 \%$ ) receiving 12 weeks of LCD showed that $50 \%$ of the study population achieved $\mathrm{HbA} 1 \mathrm{c}$ within the non-diabetes range $(<6.5 \%)$ at the end of 12 weeks on LCD, without using any antidiabetic medications $(p<0.001)$ [31]. 
In a study involving 12 overweight/obese individuals with recently diagnosed ( $<1$ year) T2DM, the effects of a six-month intensive lifestyle program comprising both physical exercise and calorie restriction were assessed. At least partial remission was achieved by $67 \%$ of the total study population and $80 \%$ of the participants who completed the study. One participant achieved complete remission with an $\mathrm{HbA1c}$ level of 5.6\% [32].

Another study evaluated the effects of restricted diet at 1, 4, and 8 weeks on the reversal of insulin resistance and beta-cell failure in 11 individuals with T2DM. The normalization of both hepatic insulin sensitivity and beta-cell function was achieved. The study concluded that the metabolic derangements underlying T2DM could be potentially reversed by acute dietary restriction on energy intake [33]. In general, individuals with lower baseline $\mathrm{HbA1c}$, taking lesser hypoglycemic medications, and with a shorter duration of diabetes are more frequently reported to have achieved diabetes remission [11].

\section{- $\quad$ Medical Nutrition Therapy}

Owing to the direct correlation between diabetes management and diet, MNT advised by a registered dietician can potentially complement the need for traditional anti-diabetic medications [26]. Medical nutrition therapy is defined as "nutritional diagnostic, therapy, and counselling services for the purpose of disease management, which are furnished by a registered dietician or nutrition professional." It is a supportive process that helps establish goals, set priorities, and create individualized action plans that promote self-care in individuals with diabetes [26]. The components of MNT are nutrition screening/referral, assessment, diagnosis, intervention, monitoring, evaluation, documentation, and outcome management systems. It is important to note that MNT is not the same as diabetes selfmanagement training and also may require ethnicity-specific adjustments. [26,34]. The effectiveness of MNT in T2DM was demonstrated by the Diabetes Remission Clinical Trial (DiRECT), which showed that weight loss associated with lifestyle intervention caused diabetes remission in $46 \%$ of study participants after one year. The remission rate was linked to the extent of weight loss, increasing progressively from $7 \%$ to $86 \%$ after 1 year, concurrent with an increase in weight loss from $0-5 \mathrm{Kg}, 5-10 \mathrm{Kg}$, $10-15 \mathrm{Kg}$, and $\geq 15 \mathrm{Kg}$ [35].

\section{- Physical Activity}

It has been substantiated by ample evidence that short-duration T2DM can be reversed to non-diabetic blood glucose levels through significant weight loss. Further, sustainable daily physical activity is an essential component of long-term weight control [36]. The Nutrition Practice Guideline (NPG) recommends an individualized physical activity plan for diabetes. The guideline suggests the achievement of $\geq 150 \mathrm{~min} /$ week of moderateintensity (50-70\% of maximum heart rate) aerobic physical activity for at least 3 days per week, without any gap of two consecutive days without exercise [37]. It is also important to advise the maintenance of usual physical activity and to avoid any sudden exercise program during the weight-loss phase [36].

It is not only important to design and recommend strict lifestyle measures for the reversal of diabetes but equally important to ensure that these interventions are cost effective, less resource intensive, and largely scalable at the population level. A recently conducted randomized controlled cohort study in southern India assessed such a peer-led, low-cost, scalable, lifestyle intervention in individuals of South Asian descent and found it to be helpful in improving diabetes and lowering other cardiovascular risk factors [38-40].

\subsection{Bariatric Surgery}

Bariatric surgery is well recognized as a potential treatment option for morbid obesity and associated metabolic disorders, such as T2DM. Bariatric surgery for the management of adults with T2DM is approved for those with BMI $>40$ or $>35 \mathrm{~kg} / \mathrm{m}^{2}$ along with obesityrelated comorbidities. The most common bariatric surgeries are sleeve gastrectomy (SG) and RYGB [11]. The five-year follow-up outcomes of the Sleeve vs. Bypass (SLEEVEPASS) randomized clinical equivalence trial reported partial or complete remission of T2DM in $45 \%$ of RYGB patients and $37 \%$ of SG patients [41]. These findings were aligned with 
other similar studies that demonstrated long-term T2DM remission in about one-third of patients undergoing bariatric surgery [11]. The large prospective cohort study, Longitudinal Assessment of Bariatric Surgery-2 (LABS-2), evaluated the incidence and remission rates of diabetes following laparoscopic gastric banding (LAGB) and RYGBP. After 3 years, 30.2\% of LAGB patients and $68.7 \%$ of RYGB patients were in remission, and the remission was progressively higher with an increase in weight loss post-surgery [42].

\section{Role of Medications in Achieving T2DM Remission}

Pharmacotherapy is an essential component of non-surgical modalities for T2DM remission. There are three classes of non-insulin glucose-lowering drugs: insulin sensitizers, nutrient load reducers, and insulin secretagogues [43]. Therapeutic agents that lower insulin resistance in people with T2DM are known as insulin sensitizers [44]. Insulin sensitizers can be direct acting, such as metformin and pioglitazone, or indirect acting through counter-regulatory hormone pathways, such as pramlintide and bromocriptine. Similarly, insulin secretagogues are either direct acting, such as sulfonylureas and meglitinides, or indirect acting via the incretin pathway, such as dipeptidyl peptidase-4 inhibitor (DPP4i) and glucagon-like peptide 1 receptor agonists (GLP1RAs). Nutrient load reducers are also of two types: absorption enhancers, such as alpha glucosidase inhibitors, and excretion enhancers, such as sodium-glucose cotransporter 2 inhibitors (SGLT2is) [43].

Another concept of calorie restriction in patients with T2DM involves the use of calorie restriction mimetics [45,46]. Calorie restriction (CR) is defined as a decreased amount of calorie consumption compared to previous intake or that which is comparable to matched controls, without any malnutrition [46]. A calorie restriction of 30-40\% improved morbidity and mortality, particularly by reducing the development of glucose intolerance and cardiovascular disease [46]. Calorie restriction mimetics (CRMs) represents a class of medication that induces similar effects to those of $\mathrm{CR}$, including the de-acceleration of aging and the improvement of health and lifespan [46]. In this regard, several noninsulin glucose-lowering drugs can also be considered as CRMs, such as alpha glucosidase inhibitors, which delay the uptake of glucose from the gut by delaying the breakdown of complex carbohydrates, appetite-suppressing GLP1RA, and calorie-wasting SGLT2i [45,46].

\subsection{Insulin Sensitizers in T2DM Remission}

A study assessed the effects of metformin and pioglitazone combination on achieving long-term glycemic control in 373 people with T2DM ( $<24$ months duration). The participants were administered a triple-drug combination of metformin, gliclazide, and pioglitazone. Once controlled, the doses of gliclazide were reduced if the blood glucose levels decreased. Pharmacological remission was defined as the maintenance of blood glucose levels in the normal range for more than six months, without the use of sulfonylureas. After using triple-drug therapy, $36.3 \%$ of the study population achieved pharmacological remission. The study inferred that insulin sensitizers, such as pioglitazone in combination with metformin, can induce diabetes remission in individuals with T2DM [47].

\subsection{Sodium-Glucose Cotransporter-2 Inhibitors in T2DM Remission}

In a case report, a 43 -year-old man with a BMI of $26 \mathrm{~kg} / \mathrm{m}^{2}$, advanced insulin resistance, $\mathrm{HbA} 1 \mathrm{c} 10.3 \%$, fatty liver, and pancreatic beta-cell dysfunction was given comprehensive therapy, including metformin and SGLT2i, for 18 months. After 18 months of comprehensive therapy, the person's glycemic control was nearly normal (HbA1c 5.3\%), and their BMI was lowered to $21.3 \mathrm{~kg} / \mathrm{m}^{2}$. These effects were observed in spite of the discontinuation of all glucose-lowering medications. This real-world clinical evidence demonstrated that diabetes remission and normal body weight could be effectively achieved in persons with newly diagnosed T2DM by a combination therapy of metformin and SGLT2i [48]. 


\subsection{The Alpha Glucosidase Inhibitor: Another Potential Candidate for T2DM Remission}

In an RCT involving 187 drug-naïve persons with newly diagnosed T2DM, the efficacy and safety of metformin monotherapy was compared with a fixed-dose combination of voglibose plus metformin. At 24 weeks, the reductions in $\mathrm{HbA} 1 \mathrm{c}$ levels were $-1.62 \% \pm 0.07 \%$ in the voglibose plus metformin group and $-1.31 \% \pm 0.07 \%$ in the metformin group $(p=0.003)$. Weight loss was also significantly higher in the voglibose plus metformin group as compared to metformin monotherapy $(-1.63 \mathrm{~kg}$ vs. $-0.86 \mathrm{~kg}$, $p=0.039$ ). Further, the number of people achieving target $\mathrm{HbA} 1 \mathrm{c}$ levels was significantly higher in the voglibose plus metformin group $(p=0.002$ for $\mathrm{HbA} 1 \mathrm{c}<6.5 \%$ and $p=0.039$ for $\mathrm{HbA} 1 \mathrm{c}<7 \%$ ). The study showed that voglibose could be useful in achieving T2DM remission [49].

An observational study evaluated the effectiveness of voglibose in preventing the development of T2DM in high-risk individuals. A total of 66 eligible persons with impaired glucose tolerance, also following regular exercise and a standard diet, were randomly assigned to receive voglibose or placebo. With an average treatment of 48.3 weeks, voglibose was better than placebo $(p=0.0024)$, as voglibose-treated persons had a lower risk of progression to T2DM, and a greater number of persons achieved normoglycemia in this group as compared to the placebo group. The study showed that lifestyle modification plus voglibose can lower the risk of T2DM development in high-risk individuals with impaired glucose tolerance [50].

\section{T2DM Remission as the Key Treatment Goal: The Future Is Not So Far}

The paradigm of diabetes care and treatment has been evolving continuously. The approaches for treating diabetes, measuring glycemia, and assessing glycemic targets have been changing, as evident from the introduction of practices and concepts such as bariatric surgery, continuous glucose monitoring system, and the time range of diabetes care [12]. Similarly, there has been a constant effort to assess the potential of achieving diabetes remission through different modalities in real-world practice. With gradual accumulation of clinical evidence, hopes regarding the achievement of diabetes remission have been raised [12]. According to recent studies, comprehensive lifestyle changes, specific diets, weight reduction, and short-term intensive glucose-lowering therapy were associated with the achievement of diabetes remission in up to $50 \%$ of participants [51]. Therefore, achieving diabetes remission is possible in real-world practice and can be considered as an alternative to traditional diabetes management. However, further clinical studies and an in-depth understanding of the mechanisms underlying diabetes remission with different strategies are warranted. Healthcare providers are also required to be made aware and educated about the possibility of diabetes remission in their practice [11].

\section{Patient Selection Criteria for Different Remission Strategies}

As all diabetes patients do not equally benefit from different remission modalities, patients should be carefully selected for each remission strategy. According to the recent guidelines by the ADA, metabolic surgery should be a recommended for screened surgical T2DM patients with BMI $\geq 40 \mathrm{Kg} / \mathrm{m}^{2}$ (BMI $\geq 37.5 \mathrm{~kg} / \mathrm{m}^{2}$ in Asian Americans) and in adults with BMI $35.0-39.9 \mathrm{~kg} / \mathrm{m}^{2}$ (32.5-37.4 kg/m² in Asian Americans) who failed to achieve durable weight loss and improvement in comorbidities (including hyperglycemia) with non-surgical methods [52]. Patients selected for metabolic surgery should be assessed for social and situational circumstances and comorbid psychological conditions, which can potentially interfere with the outcomes of metabolic surgery [52].

Regarding meal patterns, every diabetes patient should be provided with individualized meal planning. The ADA suggests that both at the time of diagnosis and as needed throughout the lifespan, every individual with diabetes should be referred to a registered dietician nutritionist for individualized MNT [53]. Patient selection should be based on the evidence of the benefits from a specific remission strategy [54]. Patient selection criteria for a low-carbohydrate diet could be prediabetes patients (HbA1c 5.7-6.5\%) or T2DM 
patients $(\mathrm{HbA} 1 \mathrm{c}>6.5 \%)$ [54]. Physical activity in addition to exercise should be prescribed and recommended for every individual with diabetes. The recommendations should be tailored as per the specific needs of every individual. Factors such as the presence of diabetes-associated health complications, age, type of diabetes, and activity levels should be considered for specific recommendations related to physical activity [53].

Non-insulin glucose-lowering drugs have a CRM effect, which is helpful in individuals with obesity or "maladaptive anabolism" or metabolic syndrome. However, they could be deleterious in persons with minimal insulin reserves and malnutrition or in those who are calorie-deprived or cachexic. It would be inappropriate to add SGLT2i to an energymalnourished carbohydrate-deprived person. Similarly, the use of AGIs will not be useful in individuals on a low-fat diet. These drugs may be strongly favored for persons with insulin resistance and those who are unable to exercise or control their appetite [46].

\section{Conclusions}

Diabetes mellitus poses a significant global health and economic burden. Although incurable, options such as diabetes prevention, delay in onset and progression, and remission or reversal have been widely embraced in the field of diabetes care. The concept of T2DM remission has been soaring high for more than a decade, as evident from the increasing number of clinical studies. Although the concept of remission is not well defined, efforts have been made to aptly define and quantify the achievement of remission in persons with T2DM. Lifestyle modifications, such as diet modifications and physical activity modifications, along with bariatric surgery, are pivotal components for achieving T2DM remission. Newly diagnosed people with T2DM should receive formal nutritional counseling and lifestyle guidance to accomplish weight loss and lifestyle improvement. Glucose-lowering agents, such as AGI, SGLT2i, pioglitazone, and metformin, showed their potential in achieving T2DM remission. In summary, achieving diabetes remission is no more a myth but a reality. However, long-term studies on the effectiveness of various remission strategies are required.

Author Contributions: All named authors meet the International Committee of Medical Journal Editors (ICMJE) criteria for authorship for this article, take responsibility for the integrity of the work as a whole, and have given their approval for this version to be published. All authors have read and agreed to the published version of the manuscript.

Funding: This initiative was supported by Sanofi India. Medical writing-related charges were paid for by Sanofi India. The authors received no honoraria from Sanofi directly or indirectly related to the development of this publication.

Institutional Review Board Statement: This article is based on previously conducted studies and does not contain any new data collected from human participants or animals.

Informed Consent Statement: Not Applicable.

Data Availability Statement: Data sharing is not applicable to this article as no datasets were generated or analyzed during the current study.

Acknowledgments: We would like to acknowledge Rajshri Mallabadi and Shravanti Mukherjee from BioQuest Solutions Pvt. Ltd., Bangalore, for providing medical writing and editorial support in the preparation of this manuscript paid for by Sanofi India. We would also like to thank S Amarnath (Sanofi India) for his assistance in author liaising and project/process oversight during the planning and development of this review article.

Conflicts of Interest: The authors have no conflict of interest.

\section{References}

1. Papatheodorou, K.; Banach, M.; Bekiari, E.; Rizzo, M.; Edmonds, M. Complications of Diabetes. J. Diabetes Res. 2018, 2018, 3086167. [CrossRef] [PubMed]

2. International Diabetes Federation. Diabetes Atlas 9th Edition. 2019. Available online: https://www.diabetesatlas.org/en/ (accessed on 21 April 2021). 
3. Galaviz, K.I.; Narayan, K.M.V.; Lobelo, F.; Weber, M.B. Lifestyle and the Prevention of Type 2 Diabetes: A Status Report. Am. J. Lifestyle Med. 2015, 12, 4-20. [CrossRef]

4. Starfield, B.; Hyde, J.; Gérvas, J.; Heath, I. The concept of prevention: A good idea gone astray? J. Epidemiol. Community Health 2008, 62, 580-583. [CrossRef]

5. Uusitupa, M.; Khan, T.A.; Viguiliouk, E.; Kahleova, H.; Rivellese, A.A. Prevention of Type 2 Diabetes by Lifestyle Changes: A Systematic Review and Meta-Analysis. Nutrients 2019, 11, 2611. [CrossRef]

6. Mann, J.I.; De Leeuw, I.; Hermansen, K.; Karamanos, B.; Karlström, B.; Katsilambros, N.; Riccardi, G. Evidence-based nutritional approaches to the treatment and prevention of diabetes mellitus. Nutr. Metab. Cardiovasc. Dis. 2004, 14, 373-394. [CrossRef]

7. Lindström, J.; Ilanne-Parikka, P.; Peltonen, M.; Aunola, S.; Eriksson, J.G.; Hemio, K. Sustained reduction in the incidence of type 2 diabetes by lifestyle intervention: Follow-up of the Finnish Diabetes Prevention Study. Lancet 2006, 368, 1673-1679. [CrossRef]

8. Knowler, W.C.; Barrett-Connor, E.; Fowler, S.E.; Hamman, R.F.; Lachin, J.M.; Walker, E.A.; Nathan, D.M. Reduction in the incidence of type 2 diabetes with lifestyle intervention or metformin. N. Engl. J. Med. 2002, 346, 393-403.

9. Tuomilehto, J.; Lindström, J.; Eriksson, J.G.; Valle, T.T.; Hämäläinen, H.; Ilanne-Parikka, P.; Keinänen-Kiukaanniemi, S. Prevention of type 2 diabetes mellitus by changes in lifestyle among subjects with impaired glucose tolerance. N. Engl. J. Med. 2001, 344, 1343-1350. [CrossRef] [PubMed]

10. Nagi, D.; Hambling, C.; Taylor, R. Remission of type 2 diabetes: A position statement from the Association of British Clinical Diabetologists (ABCD) and the Primary Care Diabetes Society (PCDS). Br. J. Diabetes 2019, 19, 73-76. [CrossRef]

11. Hallberg, S.J.; Gershuni, V.M.; Hazbun, T.L.; Athinarayanan, S.J. Reversing Type 2 Diabetes: A Narrative Review of the Evidence. Nutrients 2019, 11, 766. [CrossRef]

12. Kalra, S.; Singal, A.; Lathia, T. What's in a Name? Redefining Type 2 Diabetes Remission. Diabetes Ther. 2021, 12, 647-654. [CrossRef]

13. Pories, W.J.; MacDonald, K.G., Jr.; Morgan, E.J.; Sinha, M.K.; Dohm, G.L.; Swanson, M.S.; Brakat, H.A.; Khazanie, P.G.; LeggettFrazier, N.; Long, S.D. Surgical treatment of obesity and its effect on diabetes: 10-y follow-up. Am. J. Clin. Nutr. 1992, 55, 582S-585S. [CrossRef] [PubMed]

14. Taylor, R. Type 2 diabetes: Etiology and reversibility. Diabetes Care 2013, 36, 1047-1055. [CrossRef] [PubMed]

15. World Health Organization. Global Report on Diabetes. 2016. Available online: https://www.who.int/publications/i/item/978924 1565257 (accessed on 21 April 2021).

16. Buse, J.B.; Caprio, S.; Cefalu, W.T. How do we define cure of diabetes? Diabetes Care 2009, 32, 2133-2135. [CrossRef] [PubMed]

17. Riddle, M.C.; Cefalu, W.T.; Evans, P.H.; Gerstein, H.C.; Nauck, M.A.; Oh, W.K.; Rothberg, A.E.; le Roux, C.W.; Rubino, F.; Schauer, P.; et al. Consensus Report: Definition and Interpretation of Remission in Type 2 Diabetes. Diabetes Care 2021, 30, dci210034.

18. Park, J.Y. Prediction of Type 2 Diabetes Remission after Bariatric or Metabolic Surgery. J. Obes. Metab. Syndr. 2018, 27, 213-222. [CrossRef] [PubMed]

19. Panunzi, S.; Carlsson, L.; De Gaetano, A.; Peltonen, M.; Rice, T.; Sjöström, L.; Mingrone, G.; Dixon, J.B. Determinants of Diabetes Remission and Glycemic Control After Bariatric Surgery. Diabetes Care 2016, 39, 166-174. [CrossRef]

20. Thom, G.; Messow, C.M.; Leslie, W.S.; Barnes, A.C.; Brosnahan, N.; McCombie, L.; Al-Mrabeh, A.; Zhyzhneuskaya, S.; Welsh, P.; Sattar, N.; et al. Predictors of type 2 diabetes remission in the Diabetes Remission Clinical Trial (DiRECT). Diabet. Med. 2020, 38, e14395. [CrossRef] [PubMed]

21. Kramer, C.K.; Zinman, B.; Choi, H.; Retnakaran, R. Predictors of sustained drug-free diabetes remission over 48 weeks following short-term intensive insulin therapy in early type 2 diabetes. BMJ Open Diabetes Res. Care 2016, 4, e000270. [CrossRef]

22. Still, C.D.; Wood, G.C.; Benotti, P.; Petrick, A.T.; Gabrielsen, J.; Strodel, W.E.; Ibele, A.; Seiler, J.; Irving, B.A.; Celaya, M.P.; et al. Preoperative prediction of type 2 diabetes remission after Roux-en-Y gastric bypass surgery: A retrospective cohort study. Lancet Diabetes Endocrinol. 2014, 2, 38-45. [CrossRef]

23. Lee, W.J.; Chong, K.; Chen, S.C.; Zachariah, J.; Ser, K.; Lee, Y.; Chen, J. Preoperative Prediction of Type 2 Diabetes Remission After Gastric Bypass Surgery: A Comparison of DiaRem Scores and ABCD Scores. Obes. Surg. 2016, 26, 2418-2424. [CrossRef]

24. Lee, W.J.; Hur, K.Y.; Lakadawala, M.; Kasama, K.; Wong, S.K.H.; Chen, S.C.; Lee, Y.C.; Ser, K.H. Predicting success of metabolic surgery: Age, body mass index, C-peptide, and duration score. Surg. Obes. Relat. Dis. 2013, 9, S379-S384. [CrossRef] [PubMed]

25. Aminian, A.; Brethauer, S.A.; Andalib, A.; Nowacki, A.S.; Jimenez, A.; Corcelles, R.; Nor, Z. Individualized Metabolic Surgery Score: Procedure Selection Based on Diabetes Severity. Ann. Surg. 2017, 266, 650-657. [CrossRef] [PubMed]

26. Morris, S.F.; Rosett, J.W. Medical nutrition therapy: A key to diabetes management and prevention. Clin. Diabetes 2010, 28, 12-18. [CrossRef]

27. Kelly, J.; Karlsen, M.; Steinke, G. Type 2 Diabetes Remission and Lifestyle Medicine: A Position Statement from the American College of Lifestyle Medicine. Am. J. Lifestyle Med. 2020, 14, 406-419. [CrossRef]

28. LeFevre, M.L. U.S. Preventive Services Task Force. Behavioral counseling to promote a healthful diet and physical activity for cardiovascular disease prevention in adults with cardiovascular risk factors: U.S. Preventive Services Task Force Recommendation Statement. Ann. Intern. Med. 2014, 161, 587-593. [CrossRef] [PubMed]

29. Artinian, N.T.; Fletcher, G.F.; Mozaffarian, D.; Kris-Etherton, P.; Horn, L.V.; Lichtenstein, A.H.; Kumanyika, S. Interventions to promote physical activity and dietary lifestyle changes for cardiovascular risk factor reduction in adults: A scientific statement from the American Heart Association. Circulation 2010, 122, 406-441. [CrossRef] 
30. American Diabetes Association. Standards of Medical Care in Diabetes-2015. Diabetes Care 2015, 38, s1-s93.

31. Bhatt, A.A.; Choudhari, P.K.; Mahajan, R.R.; Sayyad, M.G.; Pratyush, D.D.; Hasan, I. Effect of a Low-Calorie Diet on Restoration of Normoglycemia in Obese subjects with Type 2 Diabetes. Indian J. Endocrinol. Metab. 2017, 21, 776-780.

32. Ades, P.A.; Savage, P.D.; Marney, A.M.; Harvey, J.; Evans, K.A. Remission of recently diagnosed type 2 diabetes mellitus with weight loss and exercise. J. Cardiopulm. Rehabil. Prev. 2015, 35, 193-197. [CrossRef]

33. Lim, E.L.; Hollingsworth, K.G.; Aribisala, B.S.; Chen, M.J.; Mathers, J.C.; Taylor, R. Reversal of type 2 diabetes: Normalisation of beta cell function in association with decreased pancreas and liver triacylglycerol. Diabetologia 2011, 54, 2506-2514. [CrossRef]

34. Kapoor, N.; Sahay, R.; Kalra, S.L. Consensus on Medical Nutrition Therapy for Diabesity (CoMeND) in Adults: A South Asian Perspective. Diabetes Metab. Syndr. Obes. 2021, 14, 1703-1728. [CrossRef]

35. Lean, M.E.; Leslie, W.S.; Barnes, A.C.; Brosnahan, N.; Thom, G.; Mc Combie, L.; Peters, C. Primary care-led weight management for remission of type 2 diabetes (DiRECT): An open-label, cluster-randomised trial. Lancet 2018, 391, 541-551. [CrossRef]

36. Taylor, R.; Barnes, A.C. Can type 2 diabetes be reversed and how can this best be achieved? James Lind Alliance research priority number one. Diabet. Med. 2019, 36, 308-315. [CrossRef] [PubMed]

37. Franz, M.J.; MacLeod, J.; Evert, A.; Brown, C.; Gradwell, E. Academy of Nutrition and Dietetics Nutrition Practice Guideline for Type 1 and Type 2 Diabetes in Adults: Systematic Review of Evidence for Medical Nutrition Therapy Effectiveness and Recommendations for Integration into the Nutrition Care Process. J. Acad. Nutr. Diet. 2017, 117, 1659-1679. [CrossRef]

38. Thankappan, K.R.; Sathish, T.; Tapp, R.J. A peer-support lifestyle intervention for preventing type 2 diabetes in India: A cluster-randomized controlled trial of the Kerala Diabetes Prevention Program. PLoS Med. 2018, 15, e1002575. [CrossRef] [PubMed]

39. Lotfaliany, M.; Sathish, T.; Shaw, J.; Thomas, E.; Tapp, R.J.; Kappor, N.; Thankappan, K.R.; Oldenburg, B. Effects of a lifestyle intervention on cardiovascular risk among high-risk individuals for diabetes in a low- and middle-income setting: Secondary analysis of the Kerala Diabetes Prevention Program. Prev. Med. 2020, 139, 106068. [CrossRef]

40. Kapoor, N.; Lotfaliany, M.; Sathish, T.; Thankappan, K.R.; Tapp, R.J.; Thomas, N.; Furler, J.; Oldenburg, B. Effect of a Peer-led Lifestyle Intervention on Individuals with Normal Weight Obesity: Insights from the Kerala Diabetes Prevention Program. Clin. Ther. 2020, 42, 1618-1624. [CrossRef]

41. Salminen, P.; Helmiö, M.; Ovaska, J.; Jutti, A.; Leivonen, M.; Peromaa-Haavisto, P.; Hurme, S. Effect of Laparoscopic Sleeve Gastrectomy vs Laparoscopic Roux-en-Y Gastric Bypass on Weight Loss at 5 Years Among Patients with Morbid Obesity: The SLEEVEPASS Randomized Clinical Trial. JAMA 2018, 319, 241-254. [CrossRef] [PubMed]

42. Purnell, J.Q.; Selzer, F.; Wahed, A.S.; Pender, J.; Pories, W.; Pomp, A. Type 2 Diabetes Remission Rates After Laparoscopic Gastric Bypass and Gastric Banding: Results of the Longitudinal Assessment of Bariatric Surgery Study. Diabetes Care 2016, 39, $1101-1107$. [CrossRef] [PubMed]

43. Kalra, S. Classification of non-insulin glucose lowering drugs. J. Pak. Med. Assoc. 2016, 66, 1497-1498. [PubMed]

44. Zangeneh, F.; Kudva, Y.C.; Basu, A. Insulin sensitizers. Mayo Clin. Proc. 2003, 78, 471-479. [CrossRef]

45. Smith, D.L., Jr.; Orlandella, R.M.; Allison, D.B.; Norian, L.A. Diabetes medications as potential calorie restriction mimetics-a focus on the alpha-glucosidase inhibitor acarbose. Geroscience 2020, 43, 1123-1133. [CrossRef] [PubMed]

46. Kalra, S.; Jacob, J.J.; Gupta, Y. Newer antidiabetic drugs and calorie restriction mimicry. Indian J. Endocrinol. Metab. 2016, 20, 142-146. [PubMed]

47. Panikar, V.; Joshi, S.R.; Bukkawar, A.; Nasikkar, N.S. Induction of long-term glycemic control in type 2 diabetic patients using pioglitazone and metformin combination. J. Assoc. Physicians India 2007, 55, 333-337.

48. Sugiyama, S.; Jinnouchi, H.; Hieshima, K.; Kurinami, N.; Jinnouchi, K. Type 2 Diabetes Remission and Substantial Body Weight Reduction Achieved with Metformin and a Sodium-Glucose Cotransporter 2 Inhibitor. Cureus 2020, 12, e7110. [CrossRef]

49. Oh, T.J.; Yu, J.M.; Min, K.W. Efficacy and Safety of Voglibose Plus Metformin in Patients with Type 2 Diabetes Mellitus: A Randomized Controlled Trial. Diabetes Metab. J. 2019, 43, 276-286. [CrossRef]

50. Riyaz, M.S.I.; Joseph, K.N.; Saba, M. Role of voglibose in prevention of type 2 diabetes in established case of impaired glucose tolerance: An observation study. Int. J. Res. Med. Sci. 2015, 3, 1453-1456. [CrossRef]

51. McInnes, N.; Hall, S.; Sultan, F.; Aronson, R.; Hramiak, I.; Harris, S.; Sigal, R.J.; Woo, V.; Liu, Y.Y.; Gerstein, H.C. Remission of type 2 diabetes following a short-term intervention with insulin glargine, metformin, and dapagliflozin. J. Clin. Endocrinol. Metab. 2020, 105, dgaa248. [CrossRef]

52. American Diabetes Association. 8. Obesity Management for the Treatment of Type 2 Diabetes: Standards of Medical Care in Diabetes-2021. Diabetes Care 2021, 44, S100-S110. [CrossRef]

53. American Diabetes Association. 5. Facilitating Behavior Change and Well-being to Improve Health Outcomes: Standards of Medical Care in Diabetes-2021. Diabetes Care 2021, 44, S53-S72. [CrossRef] [PubMed]

54. Cucuzzella, M.; Hite, A.; Patterson, K.; Saslow, L.; Heath, R. A clinician's guide to inpatient low-carbohydrate diets for remission of type 2 diabetes: Toward a standard of care protocol. Diabetes Manag. 2019, 9, 7-19. 